\title{
Natural dynamics of a Fucus distichus (Phaeophyceae, Fucales) population: reproduction and recruitment
}

\author{
P. O. Ang, $\mathrm{Jr}^{*}$ \\ Department of Botany, University of British Columbia, Vancouver, British Columbia, Canada, V6T 1 Z4
}

\begin{abstract}
Various phenomena related to reproduction and recruitment in a population of Fucus distichus L. emend. Powell in Vancouver, British Columbia, Canada were evaluated. Using log linear analysis and tests for simple, multiple and partial associations, age and size were both found to be significant, but size slightly more so than age, as descriptors of reproductive events. Reproductive plants were found throughout the sampling period, from September 1985 to November 1987, but peaked in fall and winter of each year. Potential egg production, based on number of eggs produced per conceptacle and number of conceptacles per unit area of receptacle, is size-dependent. However, estimated monthly egg production, calculated by observed number of eggs in clusters extruded from the receptacle, is independent of plant size. Two types of recruits were monitored. Microrecruits $(<1$ mo-old of microscopic size) are germlings developed from fertilized eggs. Their numbers were assessed using settling blocks. Macrorecruits are detectable by the unaided eye and are plants appearing in the permanent quadrats for the first time. They can first be detected when about 3 to 4 mo old. The recruitment pattern of microrecruits is significantly correlated with reproductive phenology and patterns of potential and estimated monthly egg production. The pattern of recruitment of macrorecruits is negatively correlated with reproductive phenology and that of the estimated monthly egg production. Peaks in microrecruitment are not always followed by peaks in macro-recruitment. This apparent discrepancy is probably due to a differential survivorship of microrecruits over time or to the possible existence of a 'germling bank'. Patterns of survival and emergence of macrorecruits may be independent of those of microrecruits or may be unrelated to the prevailing reproductive phenology
\end{abstract}

\section{INTRODUCTION}

Reproduction and recruitment of benthic macroalgae have been the subjects of considerable interest for several decades. Reproductive phenology and/or recruitment patterns have been examined in many intertidal (e.g. David 1943, Knight \& Parke 1950, Burrows \& Lodge 1951, Edelstein \& McLachlan 1975, Niemeck \& Mathieson 1976, Gunnill 1980a, b, 1986, Ang 1985a, b) and subtidal populations (e.g. Kain 1964, 1975, Rosenthal et al. 1974, Chapman 1984a, 1986, Schiel 1985a, b, De Wreede 1986, Reed 1990). Various factors, such as light, photoperiod, salinity and temperature, have been shown to affect the initiation and development of reproductive structures (McLachlan et

\footnotetext{
- Present address: Fisheries Research Laboratory, Fisheries and Oceans Canada, PO Box 550, Halifax, Nova Scotia. Canada B3J 2S7
}

al. 1971, Bird \& McLachlan 1976), the discharge of propagules (Jaffe 1954, Norton 1981, Pringle 1986), as well as the germination and growth of recruits (Moss \& Sheader 1973, Shannon et al. 1988).

Recruitment is defined as the addition of new individuals to a population (Doherty \& Williams 1988 in Santelices 1990). Algal species produce spores or other propagules by the hundreds of thousands (Umezaki 1984, Bhattacharya 1985, Amsler \& Neushul 1989, Pacheco-Ruiz et al. 1989). Many of these spores or propagules are capable of surviving long distance dispersal (Reed et al. 1988, see also reviews by Hoffmann 1987 and Santelices 1990). However, there is currently no consensus on what constitutes a recruit in an algal population. Observations have been made either at the microscopic stage during settlement of propagules or at the macroscopic stage, when the propagules have become large enough to be visible to unaided eye. Rarely have the observations been made at both stages 
(Santelices 1990). These stages, i.e. the dispersal, microscopic and macroscopic stages, are analogous respectively to the planktonic larval stage, settlement and post-settlement stages of marine sessile animal populations. The variable rate of recruitment among marine animals and how this could affect the adult population structure has long been recognized by fisheries biologists (Sale 1990). Until recently, most animal recruitment studies assume that there is a steady stream of larvae coming into the population. The failure of any recruits to establish in the population is largely due to events related either to settlement, like absence of suitable habitat, or to post-settlement, like competition or predation (Underwood \& Fairweather 1989). It has now been shown that reproductive phenology may be decoupled from recruitment, especially in an open population (Roughgarden et al. 1988). Oceanographic currents may carry eggs or larvae away from the spawning ground to a different habitat such that the number of recruits that become available to a population is unrelated to the reproductive state of that population. Eggs and larvae experience a very high rate of mortality during dispersal. The number that eventually survives to be recruited into a population is therefore highly variable in time and space. Underwood \& Fairweather (1989) pointed out that the failure to observe any recruitment in a population may simply be due to the absence of any recruits, and not due to any physical or biological constraints on them.

Seasonal or yearly variations in recruitment have been documented in only a few algal studies (e.g. Edelstein \& McLachlan 1975, Gunnill 1980a, b, Reed \& Foster 1984). Most of these studies are based on recruits at the macroscopic stage. Given that any intermediate stage, from propagules to the final appearance in the population as small plants, is likely to experience variable mortality, it is reasonable to expect that variability in the rate of recruitment can be significant in time and space. However, much less is known about the dynamics of the microscopic stage. There is a need to relate the dynamics at this stage with those of other stages in order to better understand the process of recruitment.

Many field studies have used clearing or provision of substrata to follow growth of recruited plants to maturity and/or senescence. Tagging or mapping has been used to follow the fate of individuals. In many cases, results from these studies were used in a life table analysis, with age as a state variable, to evaluate survivorship and life expectancy (e.g. Gunnill 1980a, b, 1986. Chapman \& Goudey 1983, Dayton et al. 1984, Chapman 1986). However, the relationship between age and reproduction has not been considered in these studies. Because of their morphological plasticity, size is a better state variable as a descriptor of population dynamics than age in many higher plants and colonial animals (Harper 1977, Caswell 1989). Many algae also exhibit plasticity in morphology (Norton et al. 1981). It is therefore likely that size is also a better state variable than age as a descriptor of algal population dynamics.

The reproductive potential of algae is usually expressed in terms of per unit biomass or per unit fertile area, both of which could be a function of size (length). A minimum length requirement before reproductive structures are formed has been suggested by Knight \& Parke (1950) and Edelstein \& McLachlan (1975) for species of Fucus. More recently, reproduction in the brown alga Laminaria longicruris Pyle. has been found to be size-specific (Chapman 1986). Lazo \& McLachlan (1990) also found good correlation between size (biomass) and reproductive pattern in the red alga Chondrus crispus Stackhouse.

This paper evaluates various events related to reproduction and recruitment in Fucus distichus L. emend. Powell. The relative importance of age versus size as a descriptor of reproductive events was evaluated using log linear and association analyses. Reproductive phenology was monitored and reproductive potential, i.e. egg (zygote) production, was assessed based on plant size. Also, the temporal pattern of recruitment was monitored using settling blocks and counts of new plants appearing within permanent quadrats every month. Recruitment pattern was then correlated with reproductive phenology and pattern of egg production.

\section{MATERIALS AND METHODS}

The study area is located along the southern seawall of False Creek, Vancouver, British Columbia, Canada $\left(49^{\circ} 17^{\prime} \mathrm{N}, 123^{\circ} 7^{\prime} \mathrm{W}\right)$. The wall is ca $1.5 \mathrm{~km}$ long and is made of slabs of granite. It supports an almost pure stand of Fucus distichus. Water in the creek is brackish, with salinity usually around $15 \%$. Fucus plants form a distinct zone 1.5 to $2 \mathrm{~m}$ in width along the seawall $2.5 \mathrm{~m}$ above the Lowest Normal Tides (LNT). There is a good tidal flush in the creek and the tidal cycle is semidiurnal. Plants are exposed to air in daytime during the summer and at night during the winter

There is uncertainty about the nomenclature of the common Fucus found along the coast of Pacific North America. Scagel et al. (1989) considered this entity to be F gardneri Silva. Earlier, Rice \& Chapman (1985) grouped one sample from Central Puget Sound area in Washington state (USA) with F. evanescens C. Ag. In this paper, I follow the opinion of Powell (1957) in considering the monoecious Fucus with caecostomata as $F$, distichus and make no distinction among the subspecies. I refer in the text simply to 'Fucus'. Voucher specimens were collected and deposited at the 
University of British Columbia Phycological Herbarium (UBC).

Quadrat size and number of replicates. Individual Fucus plants are defined by the erect branch arising from the holdfast. To follow and monitor specific individuals in the population, permanent quadrats were set up at random locations within the Fucus zone. Chapman (1984b) suggested that a quadrat size of $1 / 4 \mathrm{~m}^{2}$ $(50 \times 50 \mathrm{~cm})$ is appropriate for a population with a density in the range of 500 plants $\mathrm{m}^{-2}$. I tested this in May 1985. Quadrats of $10 \times 10 \mathrm{~cm}, 20 \times 20 \mathrm{~cm} \ldots$ up to $50 \times 50 \mathrm{~cm}$ were used to count all visible Fucus plants (minimum size $=1 \mathrm{~mm}$ ) within the quadrat. Quadrats larger than $50 \times 50 \mathrm{~cm}$ were not used as it was obvious that such larger sizes would be unwieldy and impracti$\mathrm{cal}$ at this site. The density-area curve (Fig. 1A) leveled off at quadrat sizes between $40 \times 40 \mathrm{~cm}$ and $50 \times 50$ $\mathrm{cm}$, suggesting that a quadrat of this size range is appropriate for this study. To find the appropriate number of replicates that would represent the population, quadrats of different sizes were used. The density-

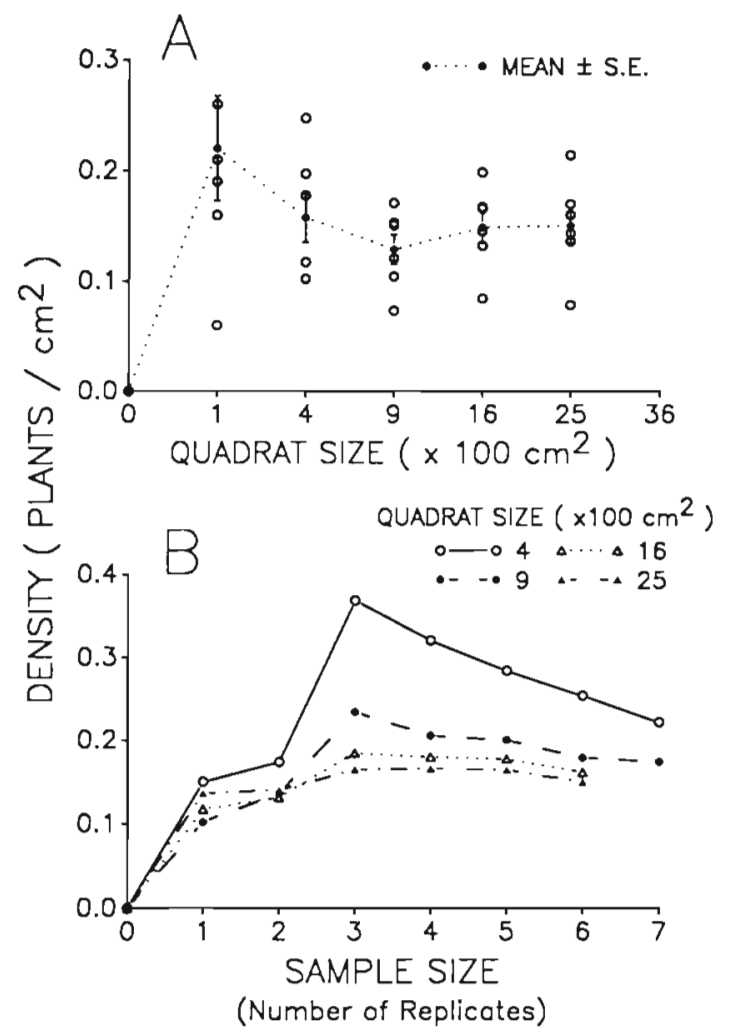

Fig. 1. Fucus distichus. (A) Density-area curve used to determine the appropriate quadrat size for use in sampling the Fucus population. Density recorded in each of the 6 replicates and mean density ( $\pm \mathrm{SE}$ ) for each quadrat size are indicated. (B) Density-sample size curve used to determine the number of replicates to be used in sampling the population. For sample size $>1$, each data point is a mean value with $\mathrm{SE}$ not shown sample size curve (Fig. 1B) leveled off at sample size of 3 replicates for quadrat size of $40 \times 40 \mathrm{~cm}$ or $50 \times 50$ $\mathrm{cm}$, indicating that when using a quadrat of this size, 3 replicates are sufficient to represent the population.

Age vs size as the descriptor of reproductive events. Three permanent quadrats of $50 \times 50 \mathrm{~cm}$ each were set up in the Fucus zone in July 1985. The quadrats were placed randomly at more or less the same height above sea level within a $200 \mathrm{~m}$ section of the seawall. Each quadrat was divided into 25 smaller squares and individuals within each square were mapped monthly from July 1985 to November 1987 (except August 1985 and November 1986). New plants in the quadrats were recorded. These plants were usually less than $5 \mathrm{~mm}$ in length when they were first detected. Size was measured from the holdfast to the tip of the longest branch. By monitoring the fate of these new plants (recruits), it was possible to evaluate the age and size at first reproduction as well as the probability of being reproductive as a function of age and size class among different cohorts. Age 1 is defined as the first month when the plant appeared in the permanent quadrat. Receptacle initiation starts at the tip of a branch. It was easy to differentiate an incipient receptacle from a more mature one, but there was no easy way to ascertain if a more mature one was fecund, i.e. was producing gametes. Sideman \& Mathieson (1983) used 4 criteria to designate a reproductive Fucus plant, namely: (1) most apices have fertile receptacles, (2) both antheridia and oogonia have clear and visible septa, (3) conceptacles are raised above the receptacular surface, and (4) mucilage extruded from the conceptacles is present. Here, first reproduction for a plant is indicated by the first appearance of receptacle(s) showing conspicuous, slightly elevated conceptacles. Because these plants were also being monitored for longevity and changes in plant length, they could not be collected, nor could the receptacles be excised to examine the conceptacles under a microscope. At times, therefore, a subjective decision was made to designate the stage of first reproduction. Ten cohorts, from September 1985 to July 1986, were included in the analyses. Cohorts initiated after July 1986 did not develop mature receptacles at the end of the observation period in November 1987.

To test whether age or size is a better descriptor of reproductive events, 2 statistical analyses were used (Caswell 1989). Log linear analysis is a qualitative test that allows an evaluation of the relative contribution of age, or size, to predicting the occurrence of a reproductive event. It also allows an evaluation of the contribution of age to this prediction when the contribution of size is known and vice versa for size and age. The second analysis is based on the Goodman-Kruskal Tau coefficient, a measure of association (Goodman \& Kruskal 1954) and partial association developed by Gray \& 
Williams (1975). This evaluates quantitatively the relative contribution of either age or size to predicting the reproductive event when the other state variable is taken into account. Partial association of size and reproduction with age and that of age and reproduction with size can then be expressed as a ratio. Size is more important than age as a descriptor of a reproductive event if the ratio is $>1$, or age is more important if the ratio is < 1 . Caswell (1989) gives a more detailed account of these analyses with applications in many plant and animal examples.

Reproductive phenology. All plants $1 \mathrm{~cm}$ or longex within the 3 permanent quadrats were measured to the closest $\mathrm{mm}$ from the holdfast to the tip of the longest branch. Their reproductive status was also recorded. In addition, 4 to 7 quadrats of $10 \times 10 \mathrm{~cm}$ were placed randomly in the Fucus zone monthly over the same period. All visible plants within the quadrats were collected and brought to the laboratory. The size of each plant was similarly measured to the nearest $\mathrm{mm}$. Receptacles from each reproductive plant were cut, placed in petri dishes and photocopied. An image of the surface area was then measured using a Kontron Image Processing System and areas of all receptacles from each fertile plant were totaled. A total of 38843 Fucus plants were censused for their reproductive status over the 29 mo of sampling.

Egg (zygote) production. Additional collections were made haphazardly, at low tide, from the site in November 1985, March, August and October 1986, and January 1987 to represent fall-winter, spring, summer, fall and winter plants respectively. Each time, in the laboratory, one receptacle from each plant was placed in a petri dish with enough filtered seawater to float the receptacle ca $1 \mathrm{~cm}$ above the bottom of the dish. This allowed eggs discharged from individual conceptacles to stay in identifiable clusters. Receptacles were kept at $16 \mathrm{~h}$ light: $8 \mathrm{~h} \mathrm{dark}$, at $15^{\circ} \mathrm{C}$ (or $10^{\circ} \mathrm{C}$ for winter collection), under low light $\left(40 \mu \mathrm{E} \mathrm{m}^{-2} \mathrm{~s}^{-1}\right)$. Discharge usually took place within $72 \mathrm{~h}$. After discharge, the receptacle was removed and the number of conceptacles in the receptacle was counted. Surface area of the receptacle was also measured using the Kontron Image Processing System.

The number of eggs in a cluster was counted under a stereo-microscope. It was very rare $(<1 \%)$ to find eggs which did not undergo cleavage, so it can be assumed that most discharged eggs were fertilized. Each cluster corresponded to the position of a conceptacle, so the number of eggs per cluster corresponded to the number of eggs discharged from individual conceptacles. However, boundaries between clusters were not always very distinct. In case of overlap, the mid line between clusters was used to partition the 2 clusters during counting. Three to five clusters were counted per receptacle, and the total number of clusters from each receptacle was also recorded.

Recruitment. The seawall is made of granite. Small chips of granite (2 to $3 \mathrm{~cm}$ in length) were collected from the site and were cemented (Poly Cement, Le Page's Ltd, Bramalea, Ontario, Canada) into $5 \times 5 \mathrm{~cm}$ blocks exposing as much of the granite surface as possible. These blocks were left for $48 \mathrm{~h}$ to cure. After curing, they were placed in an aquarium with flowing freshwater for a week, then in seawater for at least a month to leach out any possible toxic chemicals from the cement. Finally, they were cleaned with a wire brush and rinsed in freshwater. In a preliminary seeding experiment conducted in October 1985, no difference was observed between germlings growing on the granite or on the cement part of the block. There was no significant difference in the number of germlings settled on either surface (Mann Whitney $U$ test, $\mathrm{p}=$ $0.106, n=12$ ). This was also true for the recruits settled on the first set of blocks laid out in the field (Mann Whitney $U$ test, $\mathrm{p}=0.129, \mathrm{n}=14$ ).

Starting in October 1985, 24 settling blocks were placed in cement holding pockets constructed 2 mo earlier and located randomly in the field site. Every month thereafter, up to October 1987, these blocks were retrieved and replaced with a new set. The number of blocks retrieved varied depending on the loss rate. Loss rate ranged from 0 to $50 \%$. From June 1986 on, only 11 blocks were set out each month because some of the holding pockets were destroyed. Since settling blocks were put in place during the later part of each month, they were exposed to colonization by algal propagules in the subsequent month before being retrieved.

Settling blocks retrieved from the field were brought back and placed in aquaria with filtered seawater and kept in the growth chamber at environmental conditions described earlier for the egg production experiment. All these recruits were no older than 1 mo when the blocks were retrieved. They were easy to recognize because of their size (around $300 \mu \mathrm{m}$ ), and so could be counted easily under a stereo-microscope. In addition, new plants that first appeared monthly in the 3 permanent quadrats were recorded as new recruits from. July 1985 to November 1987

Statistical analyses. Data were tested for normality (Lilliefor's test) and homogeneity of variance (Bartlett's test), except for data used in distribution-free log linear and association analyses. When appropriate, data were $\log (x+1)$ transformed to meet the assumptions of parametric statistics. Other methods of transformation were also attempted

Covariation between time and size of plant was compared using ANCOVA, with fertile area (i.e. area of the receptacle) as the dependent variable. Mean number of 
eggs discharged per conceptacle among receptacles over time was evaluated using 2-level nested ANOVA The effect of fertile area on the number of conceptacles was analyzed using ANCOVA, with sampling time as the covariate. Relationships between the number of conceptacles and fertile area, and between the number of eggs and fertile area, were evaluated in a regression analysis. Pearson correlation or Spearman Rank correlation was used to relate the pattem of recruitment against reproductive phenology and pattern of egg production. All statistical analyses were performed using SYSTAT (Wilkinson 1988).

\section{RESULTS}

\section{Age vs size as the descriptor of reproductive events}

Cohorts with members becoming reproductive were divided into 5 size classes. Size class 1 included all plants $<1 \mathrm{~cm}$ in length; size class 2,1 to $<4.5 \mathrm{~cm}$, size class $3,4.5$ to $<9.5 \mathrm{~cm}$; size class $4,9.5$ to $<14.5 \mathrm{~cm}$; and size class $5, \geq 14.5 \mathrm{~cm}$. Plants were also grouped into 6 age classes: age class 1 for plants aged 1 to $3 \mathrm{mo}$; age class 2, 4 to $6 \mathrm{mo}$; age class 3,7 to $9 \mathrm{mo}$; age class 4 , 10 to $12 \mathrm{mo}$; age class 5,13 to $15 \mathrm{mo}$; and age class 6 , $>15 \mathrm{mo}$. There were only 20 plants older than $19 \mathrm{mo}$ $10.4 \%$ of total) so they were lumped together with plants in age class 6 .

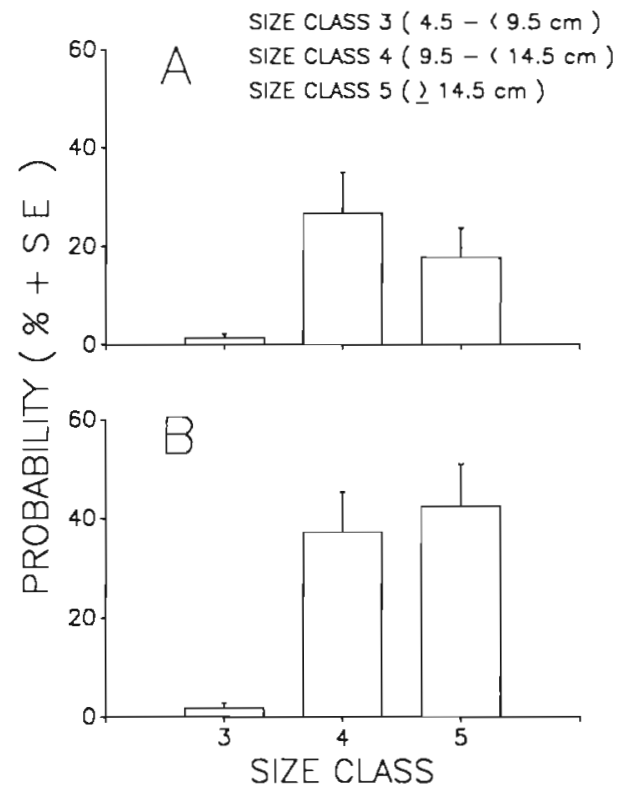

Fig. 2. Fucus distichus. (A) Mean probability (\% + SE) of becoming reproductive for the first time among plants in each size class; $(B)$ mean probability $(\%+\mathrm{SE})$ of being reproductive in each size class. Both measures were based on plants from all cohorts
Two distinctions may be made with respect to the probability of the plant becoming reproductive at any size or age. One is the size or age of first reproduction, i.e. when the receptacle was first formed, and second, the probability of being reproductive at any size or age. Several receptacles may be formed at the same time, or one after the other, at different terminal branches such that a Fucus plant could remain reproductive for prolonged periods. Or there may be time gaps between the formation of receptacles, giving the plant a semblance of iteroparity. A measure of the probability of being reproductive is therefore different from a measure of size or age of first reproduction. Both measures were based on the actual percentage of plants that were reproductive.

There was no consistent pattern in the probability of becoming reproductive for the first time in each size class. On average, plants were most likely to be 9.5 to $14.5 \mathrm{~cm}$ in size when the first receptacle was formed (Fig. 2A). Some plants were reproductive at sizes between 4.5 to $9.4 \mathrm{~cm}$. Plant smaller than $4.5 \mathrm{~cm}$ (size classes 1 and 2) never formed receptacles. In general, the larger the plant, the more likely was it to become reproductive (Fig. 2B).

Some plants as young as 7 mo old became reproductive, but reproduction could also be much delayed. No plants younger than 7 mo old ever formed receptacles. There was no discemible pattern in the probability of age at first reproduction among older plants (Fig. 3A).

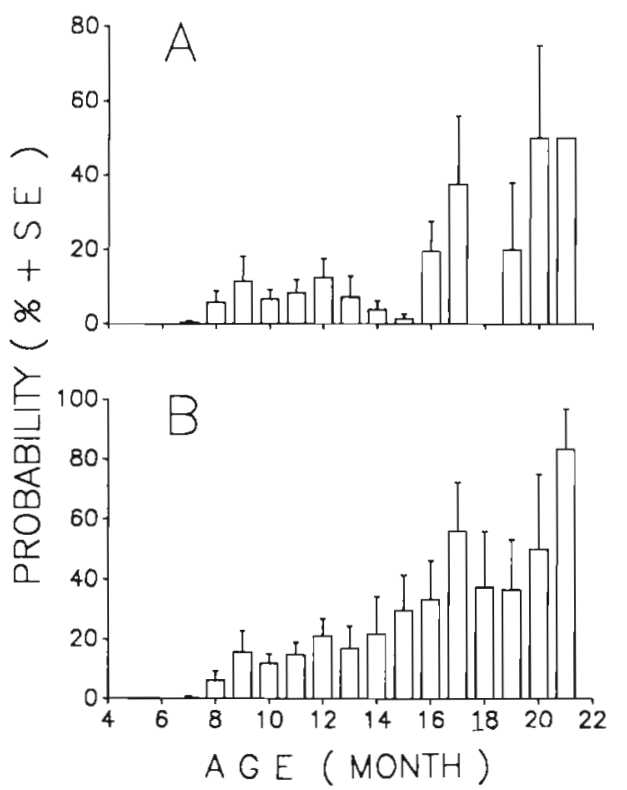

Fig. 3. Fucus distichus. (A) Mean probability $(\%+\mathrm{SE})$ of becoming reproductive for the first time at each age; $(B)$ mean probability $(\%+\mathrm{SE})$ of being reproductive at each age. Both measures were based on plants from all cohorts 
One plant from the September 1985 cohort, lost 22 mo later, never became reproductive. In contrast, the probability of being reproductive at any age generally increased with age (Fig. 3B).

Only plants in size classes 4 to 5 and age classes 3 to 6 were used in the $\log$ linear analysis and the test for partial association. Plants in size and age classes 1 to 2 never became reproductive. Only a few members of size class 3 became reproductive. Inclusion of size class 3 in the analyses resulted in more than $20 \%$ of cells in the contingency table having a frequency value less than 5, thus making results of the analyses doubtful. Exclusion of size class 3 did not affect the conclusions of the analyses.

As the likelihood of becoming reproductive increased with size as well as with age, it was possible that both age and size could be significant predictors of the reproductive fate of a plant. This is confirmed by the log linear analyses (Table 1). The results are given in terms of the $G$ statistic, which is 2 times the value of the log likelihood ratio and which approximates a chi square distribution better than the log likelihood ratio (Sakal \& Rohlf 1981). Predictions of a reproductive event from age and size taken together (Age $x$ Size $x$ Repro), from age (Age $\times$ Repro) or size (Size $\times$ Repro) alone, or from age given the known contribution from size (Age $\times$ Repro/Size) or vice versa (Size $\times$ Repro/ Age) are all highly significant. However, the index coefficients of association are small (Table 2). Analyses of associations measure the extent to which reproduction (formation of receptacle) is predicted by knowledge of age (Age $\times$ Repro) or size (Size $\times$ Repro) alone, or taken together (Age/Size $x$ Repro), or of age when size is taken into account (Age $\times$ Repro: Size) or vice versa (Size $\times$ Repro Age). A perfect association has an index coefficient of 1 . Small index coefficients suggest that only a small proportion of the variances associated with reproduction can be accounted for by the knowledge about age and/or size. The ratio of partial association (Table 2 ) indicates that size is $57 \%$ better as a predictor of reproduction than age.

Table 1 Fucus distichus. Log linear analysis on the effect of age vs size on the probability of reproduction. See text for explanation of the models

\begin{tabular}{|lccc|}
\hline Model & df & $G$ & $p$ \\
\hline Age $\times$ Size $\times$ Repro & 3 & 15.00 & 0.0002 \\
Age $\times$ Repro & 3 & 20.48 & 0.0001 \\
Size $\times$ Repro & 1 & 40.94 & $<0.0001$ \\
Age $\times$ Repro/Size & 3 & 21.88 & $<0.0001$ \\
Size $\times$ Repro/Age & 1 & 42.34 & $<0.0001$ \\
\hline
\end{tabular}

Table 2. Fucus distichus. Simple, multiple and partial associations among age and size vs reproduction. See text for explanation of the associations

\begin{tabular}{|cc|}
\hline Association & Index coefficient \\
\hline Age $\times$ Repro & 0.034115 \\
Size $\times$ Repro & 0.064782 \\
Age/Size $\times$ Repro & 0.114043 \\
Age $\times$ Repro: Size & 0.052672 \\
Size $\times$ Repro: Age & 0.082750 \\
Ratio of partial association & \\
Size/Age & 1.571034 \\
\hline
\end{tabular}

\section{Reproductive phenology}

When the whole population is considered, an additional 6th size class for plants longer than $19.4 \mathrm{~cm}$ can be designated (Fig. 4). The other 5 size classes are the same as those designated earlier. In most cases, size class 1 contained the most individuals. Size class 1 included most of the new recruits (see section on recruitment below) and was usually more sparse during fall. The pattern of frequency distribution in the other size classes was less consistent over time.

Reproductive plants were present throughout the sampling period from September 1985 to November 1987 (Fig. 5). In general, a larger proportion of plants was fertile in fall to early spring than in late spring and summer. Most fertile plants belonged to size classes 4 and 5 . The probability of being fertile in size classes 3 to 6 followed a general seasonal trend, being least

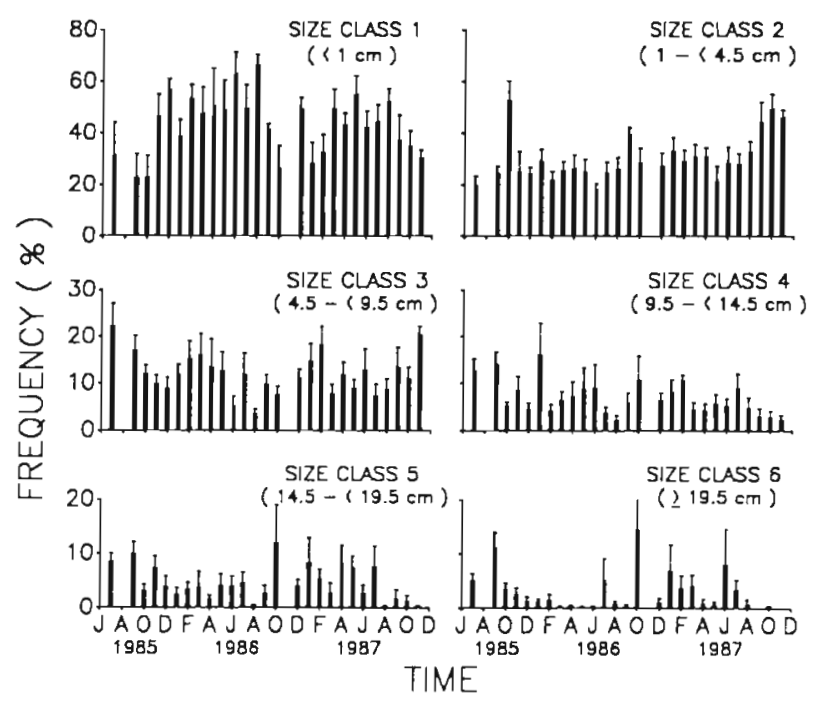

Fig. 4. Fucus distichus. Percentage $(\%+\mathrm{SE})$ frequency distribution of individuals divided among 6 size classes. The individuals were sampled monthly from July 1985 to

November 1987, except August 1985 and November 1986 


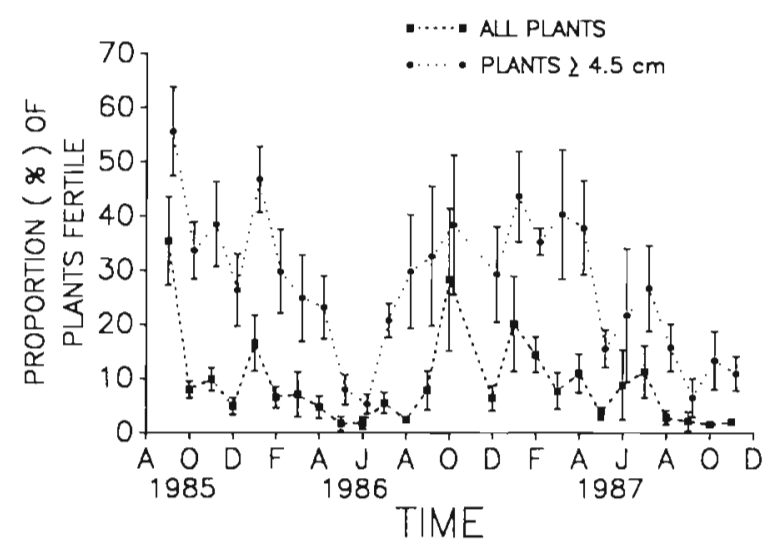

Fig. 5. Fucus distichus. Percentage $(\% \pm$ SE) of plants with receptacles from September 1985 to November 1987. Percentage calculated as number of fertile plants divided by total number of all plants, or by number of plants $\geq 4.5 \mathrm{~cm}$ long (plants in size class 3 and above)

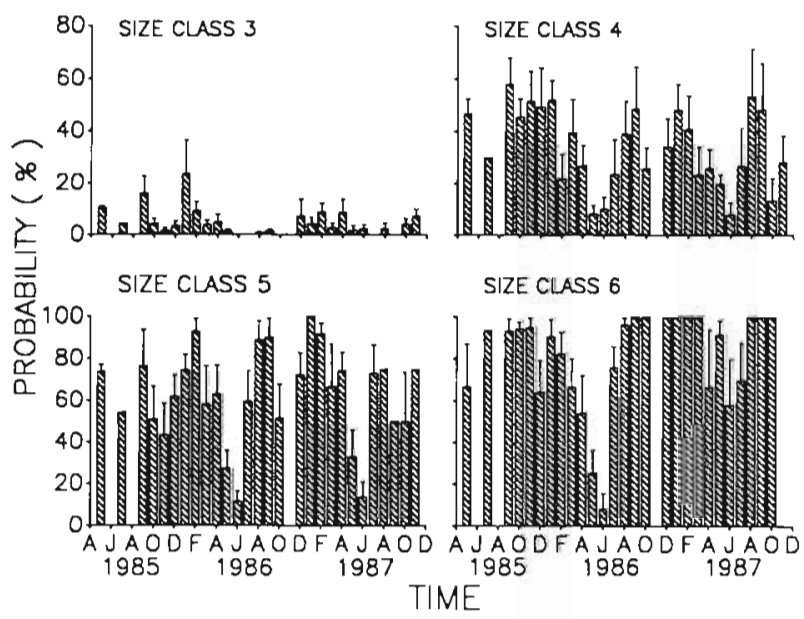

Fig. 6. Fucus distichus. Probability $(\%+\mathrm{SE})$ of being reproductive among plants within each size class. Individuals were sampled monthly from September 1985 to November 1987. except November 1986. No fertile plant was found in size classes 1 and 2

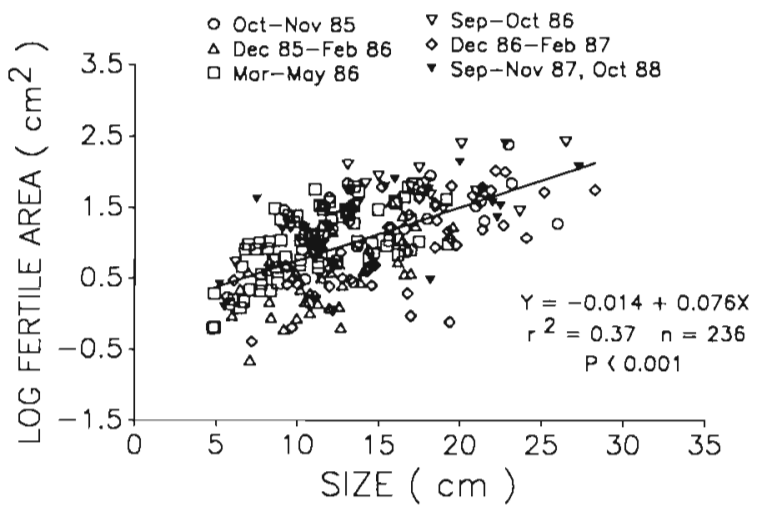

Fig. 7. Fucus distichus. Relationship between log fertile area and plant size for pooled data from all seasons except summers 1986, 1987 and spring 1987 likely in early summer, and most likely in fall and winter (Fig. 6). Plants in size class 6 were almost always fertile in fall and winter.

The slopes of the regression between fertile area and plant size are not significantly different over time (ANCOVA, Time $\times$ Size, $F_{25,250}=1.079, p=0.367$ ), so all the data can be pooled. However, regressions for summers (June to August 1986 and 1987) and for spring (March to May 1987) are not significant, so only data from other seasons which show significant regressions were pooled. The resulting linear regression line (Fig. 7) is significant and accounts for $37 \%$ of the variation of the pooled data. If all the data had been pooled, i.e. including those from summers 1986, 1987 and spring 1987, the regression line would still be significant but would have accounted for only $28 \%$ of the variation within the data $(\log Y=0.044+0.069 X$, $\mathrm{r}^{2}=0.28, \mathrm{p}<0.001, \mathrm{n}=302$ ).

\section{Egg production}

The number of eggs discharged from the conceptacles was variable (Table 3). Results from a 2-level nested ANOVA suggest that the number discharged per conceptacle is significantly different among receptacles $\left(F_{20,100}=2.789, \mathrm{p}<0.001\right)$ and over time $\left(F_{4,100}=\right.$ 22.380, $\mathrm{p}<0.001)$. The difference among times is mainly due to the low number of eggs discharged from receptacles in August 1986 (Table 3). On average, 188 eggs ( $\pm 15.63 \mathrm{SE}$ ) were discharged per conceptacle in August 1986 and about double that number $366 \pm$ 12.91) was discharged in each of the other months.

To test the difference between number of eggs discharged and the number of eggs that are potentially available within a conceptacle, in January 1987, 5 conceptacles each from 5 receptacles were smeared and the number of oogonia within each conceptacle was counted. Typically, 8 eggs are produced per oogonium in Fucus (Bold \& Wynne 1985), so the number of oogonia multiplied by 8 should give the potential number of eggs that could become available. Some of the oogonia were very small $(<200 \mu \mathrm{m})$ and the eggs they contained were about half, or less than half, the size of those in the bigger oogonia. It is very likely that these were immature oogonia and would presumably continue to develop and discharge eggs at a later time. An examination of the receptacles used in the egg production experiment revealed the presence of a number of immature oogonia in an otherwise empty conceptacle. The actual number of eggs discharged per conceptacle ( $353 \pm 23.7 \mathrm{SE}$ ) is significantly different from the number of eggs present inside a conceptacle $(979 \pm 89.4)$ (2-level nested ANOVA, $F_{1.40}$ $=102.357, \mathrm{p}<0.001)$. 
Table 3. Fucus distichus. Mean number of eggs ( \pm SE) discharged from 5 conceptacles per receptacle at different time periods

\begin{tabular}{|c|c|c|c|c|c|}
\hline \multirow[t]{2}{*}{ Receptacle } & \multicolumn{5}{|c|}{ Date ${ }^{*}$} \\
\hline & Nov $85^{d}$ & $\operatorname{Mar} 86^{\mathrm{a}}$ & Aug $86^{b}$ & Oct $86^{a}$ & $\operatorname{Jan} 87^{a}$ \\
\hline 1 & $285.0 \pm 25.7$ & $388.0 \pm 36.6$ & $225.8 \pm 14.3$ & $238.8 \pm 25.1$ & $351.0 \pm 33.5$ \\
\hline 2 & $261.2 \pm 60.4$ & $508.6 \pm 43.2$ & $97.0 \pm 7.2$ & $309.4 \pm 53.9$ & $333.2 \pm 67.3$ \\
\hline 3 & $443.6 \pm 36.5$ & $407.8 \pm 26.6$ & $201.4 \pm 18.7$ & $400.6 \pm 42.6$ & $209.6 \pm 22.9$ \\
\hline 4 & $399.4 \pm 70.5$ & $315.0 \pm 76.8$ & $153.0 \pm 22.4$ & $447.4 \pm 54.9$ & $307.0 \pm 60.9$ \\
\hline 5 & $370.6 \pm 37.8$ & $298.4 \pm 65.6$ & $182.6 \pm 29.8$ & $373.8 \pm 51.2$ & $351.6 \pm 35.8$ \\
\hline
\end{tabular}

Results from an ANCOVA indicate that the relationship between fertile area and the number of conceptacles is not significantly different among seasons (Area $\times$ Time, $F_{3,62}=2.456, p=0.071$, except for August 1986 (Area $\times$ Time, $F_{4,72}=6.319, \mathrm{p}<0.001$ ). This relationship is curvilinear for pooled data representing all other seasons except August 1986 (Fig. 8), and

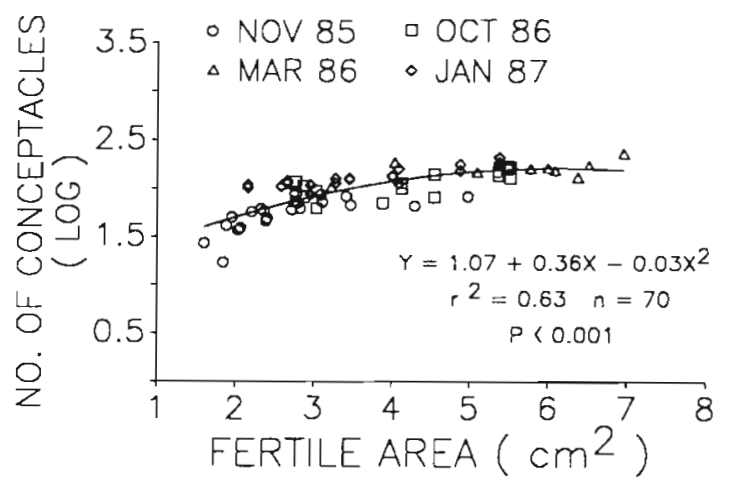

Fig. 8. Fucus distichus. Relationship between log number of conceptacles and area of receptacles for pooled data from November 1985. March 1986, October 1986, and January 1987

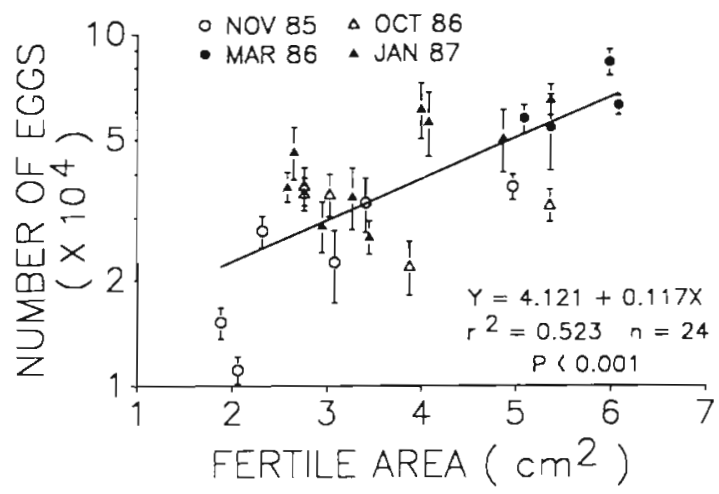

Fig. 9. Fucus distichus. Relationship between mean number of eggs ( \pm SE) and area of receptacle for pooled data from November 1985, March 1986, October 1986, and January 1987. Each data point represents mean number of eggs from 5 conceptacles multiplied by the number of conceptacles in each receptacle accounts for $63 \%$ of the variation. The mean number of eggs produced by a receptacle with a given surface area can therefore be obtained by multiplying the mean number of eggs produced per conceptacle by the number of conceptacles per receptacle and regressed against the area of the receptacle (Fig. 9). The regression line is linear and significant.

Regression lines from Figs. $7 \& 9$ can be used to estimate the number of eggs produced from any size of plant $\geq 4.5 \mathrm{~cm}$ and for times other than the summers of 1986 and 1987, and the spring of 1987, using the following equations:

$$
\begin{aligned}
& \log Y=4.121+0.117 X \\
& \log X=-0.014+0.076 Z
\end{aligned}
$$

where $Y=$ number of eggs; $X=$ area of the receptacle (fertile area); and $Z=$ size of plant. Because of the lack of a significant relationship between fertile area and the size of plants in summer, mean area was used to predict the number of conceptacles and then multiplied by mean number of eggs per conceptacle for August to give the number of eggs produced per plant. This was also done for plants in spring 1987.

Not all conceptacles from the same receptacle produced eggs at the same time. Receptacles also persisted through a period longer than 1 mo. Hence, calculations made above give the potential number of eggs that can be produced during the life span of the receptacles as measured at a particular point in time.

The number of new plants recruited into a population may be more closely related to the actual number of eggs discharged at a particular time, than to the potential number. Actual number of eggs discharged can be calculated by multiplying the number of eggs in a cluster by the number of clusters produced by the receptacle at one time. Results of ANCOVA indicate that the relationship between the area of a receptacle and the number of egg clusters is not significantly different over time (Area $\times$ Time, $F_{3,19}=1.040, \mathrm{p}=$ 0.397 ). This relationship is always non-significant 


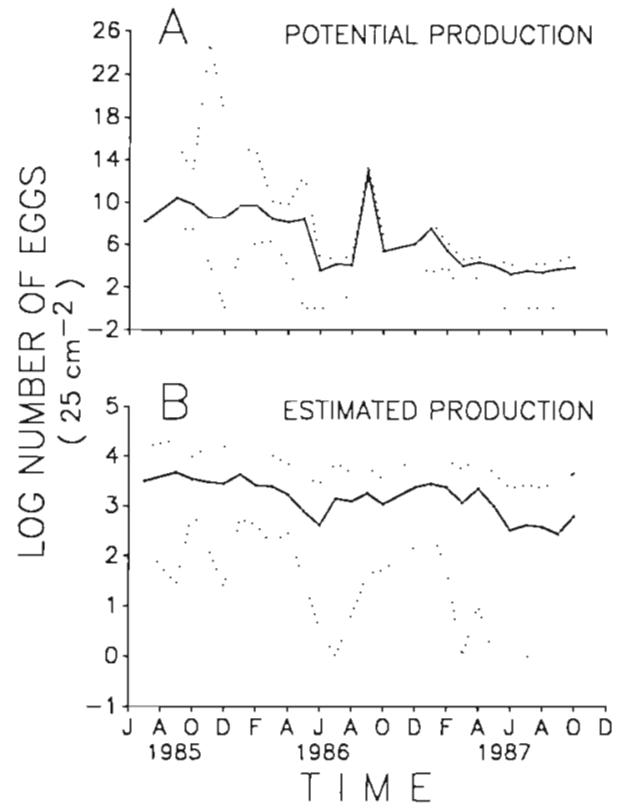

Fig. 10. Fucus distichus. (A) Potential and (B) estimated number of eggs produced per $25 \mathrm{~cm}^{2}$ of Fucus zone every month, with maximum and minimum $95 \%$ confidence limits of the estimates. See text for more details on how the calculations were made

(linear regression, $\mathrm{r}^{2}=0.049, \mathrm{p}=0.269, \mathrm{n}=27$ ). The number of clusters produced, and hence the actual number of eggs, is independent of the size of the receptacle, hence also of plant size. The mean number of eggs in each cluster multiplied by the mean number of clusters produced by each receptacle at any one time was therefore used in the calculation for the estimated number of eggs produced monthly by each plant.

Density of Fucus plants and the percentage of fertile plants in different size classes varied over time. Assuming no significant immigration of eggs from other Fucus populations, the potential and estimated number of eggs available in the population at any one time would not only depend on the number of eggs produced by each plant, but would also depend on plant density and the probability of these plants being fertile. The potential and estimated number of eggs available in the population at any one time is therefore better projected on a per area rather than on a per plant basis. In either case, however, the production pattern exhibited should be comparable. The potential and estimated number of eggs per $25 \mathrm{~cm}^{2}$ of ground surface in the Fucus zone produced by the population from 1985 to 1987, with maximum and minimum $95 \%$ confidence limit, differs by about 5 orders of magnitude (Fig. 10). In both cases, production of eggs is highly correlated with the reproductive phenology of the plants (Table 4).

\section{Recruitment}

Two types of recruits were considered. Microrecruits collected on settling blocks presumably developed from eggs recently (i.e. within 1 mo) discharged. They were small and could not be seen with the unaided eye. It usually took at least 3 to 4 mo before these recruits became visible, i.e. became $1 \mathrm{~mm}$ or bigger (Ang 1991a). Visible plants appearing for the first time in the permanent quadrats and recorded as macrorecruits were therefore older, and must have developed from eggs discharged at least 3 or 4 mo earlier. Monthly mapping of individuals in each permanent quadrat allowed the detection of any new plants that appeared in the quadrat. Although there was always a possibility of counting the same individual as a new recruit over successive months, this was a potential problem only during April to July 1986 when the number of recruits was very high (Fig. 11). In case of doubt, an individual was assumed to be an older plant. A decision like this had to be made in $<10 \%$ of the cases. Hence, while there could be an underestimation of the number of macrorecruits that actually appeared in the permanent quadrats, the extent of this underestimation was probably minimal. A total of 25508 microrecruits and 29537

Table 4. Fucus distichus. Correlation matrices showing Pearson Correlation Coefficient ( $r$ ) (in italics) or Spearman Rank Correlation Coefficient $\left(r_{s}\right)$ between variables. $\log _{10}$-transformed number of microrecruits was used in Pearson correlation analysis. Number of cases in parentheses

\begin{tabular}{|c|c|c|c|c|c|c|}
\hline \multirow{2}{*}{$\begin{array}{l}\text { Variable } \\
\text { Microrecruits }\end{array}$} & \multicolumn{2}{|c|}{ Reproductive phenology } & \multicolumn{2}{|c|}{ Estimated egg production } & \multicolumn{2}{|c|}{ Potential egg production } \\
\hline & $0.567^{\cdots}$ & $(24)$ & $0.473^{\circ}$ & $(23)$ & $0.396^{\circ}$ & (23) \\
\hline Microrecruits ( 1 mo antecedent) & $0.525^{\cdots}$ & (24) & 0.372 & (24) & 0.279 & (24) \\
\hline Macrorecruits & $-0.407^{\circ}$ & (27) & $-0.354^{\circ}$ & $(26)$ & -0.080 & (26) \\
\hline Macrorecruits (1 mo antecedent) & -0.277 & (24) & -0.211 & (24) & 0.031 & (24) \\
\hline Macrorecruits ( 2 mo antecedent) & -0.257 & $(25)$ & -0.098 & (24) & 0.082 & (24) \\
\hline Macrorecruits ( 3 mo antecedent) & -0.309 & (23) & -0.010 & (23) & 0.219 & (23) \\
\hline Reproductive phenology & & & $0.759 \cdots$ & (26) & $0.531^{\cdots}$ & (26) \\
\hline \multicolumn{7}{|c|}{$\cdot 0.01<p \leq 0.05 ; \cdots 0.001<p \leq 0.01 ; \cdots p \leq 0.001$} \\
\hline
\end{tabular}




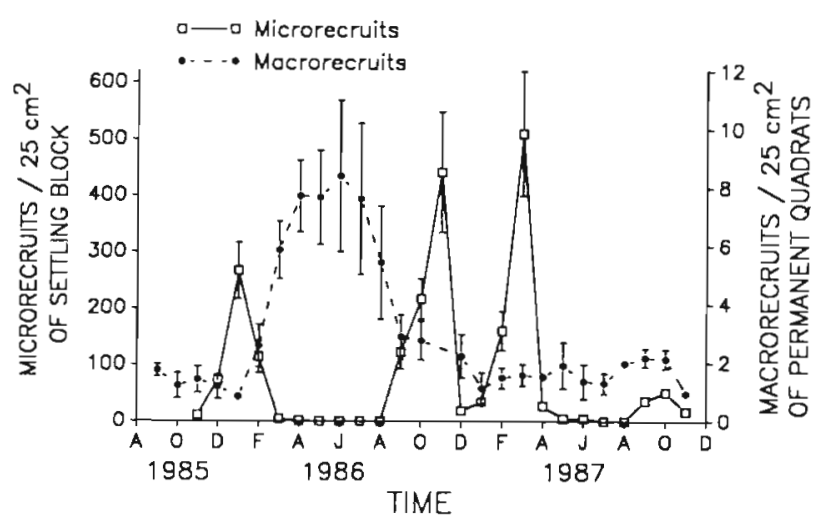

Fig. 11 Fucus distichus. Monthly mean number of microrecruits ( \pm SE) counted on $25 \mathrm{~cm}^{2}$ settling blocks and monthly mean number of macrorecruits ( \pm : SE) recorded per $25 \mathrm{~cm}^{2}$ of permanent quadrats

macrorecruits were censused throughout the 2 yr sampling period.

Three big pulses of microrecruits were recorded within this period (Fig. 11). These pulses ranged from 266 plants $( \pm 52.5 \mathrm{SE}$ ) per $5 \times 5 \mathrm{~cm}$ settling block in January 1986 , to 509.5 plants ( $\pm 115.5 \mathrm{SE}$ ) per block in March 1987 However, they were not always associated with peaks in fertility. Nevertheless, since the blocks were exposed to colonization for only a month, and presumably microrecruits developed only from eggs released recently, the recruitment pattern recorded on these blocks should be related to the reproductive pattern at the time when these blocks were retrieved (i.e. after having been exposed for a month for colonization), or that of the preceding month (i.e. 1 mo antecedent), at the time when blocks were laid. This is confirmed by a highly significant positive correlation between the reproductive phenology and the overall recruitment pattern (Table 4). Although there were no microrecruits collected in the summer months of both years, the possible presence of eggs during those periods is suggested by the estimated monthly egg production. There is a significant positive correlation between both the estimated and potential egg production and the recruitment patterns over the 2 yr period (Table 4)

The pattern of macro-recruitment in permanent quadrats is very different from that of micro-recruitment. Macrorecruits were present throughout the sampling period and peaked only once - during spring to summer of 1986. Given that it took at least 3 to 4 mo for a microrecruit to become a macrorecruit, the peak in spring to summer of 1986 appeared to follow the first big pulse of microrecruits and a high fertility period in the preceding few months. However, such a pattern was not repeated in the following year although the population experienced another peak of fertility in fall to winter of
1986 and 2 more pulses of microrecruits. Unlike the micro-recruitment pattern, macro-recruitment did not peak and fall abruptly. Interestingly, there is a significant negative correlation between the pattern of macrorecruitment and reproductive phenology (Table 4), as well as with the estimated monthly egg production pattern. No significant correlation could be detected between macro-recruitment pattern of up to 3 mo antecedent and reproductive phenology, nor with estimated and potential egg production patterns (Table 4).

\section{DISCUSSION}

A minimum size requirement before commencement of reproduction has been reported for many higher plants (see Harper 1977 for examples). This phenomenon has received considerably less attention among algae. Size-specific first reproduction was mentioned mainly as a part of studies on reproductive phenology. Among intertidal fucoids, Knight \& Parke (1950) observed that young plants of Fucus vesiculosus L. usually attained a length of 15 to $20 \mathrm{~cm}$, and for $F$. serratus L., a little longer at 18 to $25 \mathrm{~cm}$, before forming receptacles. Niemeck \& Mathieson (1976) noted that all reproductive plants of $F$. spiralis $\mathrm{L}$. were longer than 9.5 $\mathrm{cm}$ during July to September, the period of maximum reproduction. This latter size range is similar to what I found for $F$ distichus.

There is more information on age-specific reproduction. Except for short-lived algae which reproduce and die within the same year or season, most long-lived $(>1 \mathrm{yr}$ ) algae tend to reproduce in their second year and/or thereafter (see review by De Wreede \& Klinger 1988). However, there are some exceptions. Similar to my observations, Knight \& Parke (1950) and Edelstein \& McLachlan (1975) noted that a small number of Fucus individuals became reproductive in their first year In most studies on age-specific reproduction, age is based on the time when the young plant was first detected in the field or in clearings. But the time lapse between actual recruitment as a spore or zygote and when the recruit becomes visible may vary, so the actual age at first reproduction may vary accordingly. Work by Chapman (1986) on Laminaria longicruris probably achieved the closest estimate of true age of reproduction.

In this population of Fucus I studied, both age and size should ideally be taken into consideration when describing reproduction. Low association indices of age and/or size (Table 2) suggest that knowledge about other state variables, such as biomass and number of bifurcations, may also contribute significantly to the prediction of reproduction. However, it is not possible to measure all state variables in a population study. 
Considering age versus size, the use of size offers some logistic advantages over the use of age. As mentioned earlier, most studies on age involved tagging or mapping and monitoring of plants over a period of time. The actual age of plants could only be estimated reliably if monitoring starts from the time when plants first enter the population. Other aging techniques may be available, such as counting of growth rings in kelps (Novaczek 1981, De Wreede 1984, 1986) or air bladders in Ascophyllum nodosum (L.) Le Jol. (Cousens 1985); their applicability is, however, rather specific. These techniques also have other limitations. Counting growth rings necessitates the destruction of the plant. Although some morphological characters like stipe length may be related to age, and hence may be used to estimate age (De Wreede 1984), this relationship is site-dependent (De Wreede 1984, Hymanson et al. 1990). The time between initial recruitment and formation of the first air bladder in Ascophyllum varies among plants (Baardseth 1970, Cousens 1985, Vadas \& Wright 1986). Also, absolute age cannot be determined for this species because of vegetative regeneration (Keser et al. 1981).

Size measurement is more straightforward. While ways to monitor changes in sizes of individuals may be equally tedious, the history of individuals under study need not be known. Although my study, as well as studies by Chapman (1986) and Lazo \& McLachlan (1990), indicated that size is the better predictor of reproductive events, the examples are too few to justify making a generalization about all algae. The use of size in population studies also needs to be further evaluated with respect to other demographic parameters such as growth and mortality (see Ang 1991b).

A general trend of reproductive phenology for temperate intertidal algae seems to be that, with some exceptions, peaks of reproduction occur either in winter (fall to winter or winter to spring) or in summer (spring to summer or summer to fall) (Hoffman 1987). The pattern varies from place to place and from species to species. Ascophyllum nodosum (David 1943), Fucus vesiculosus (Knight \& Parke 1950), F. spiralis (Niemeck \& Mathieson 1976) and Postelsia palmaeformis Ruprecht (Dayton 1973) had reproductive peaks in summer, while F. serratus (Knight \& Parke 1950), F. distichus ssp. distichus (Edelstein \& McLachlan 1975) and Pelvetia fastigiata (J. Ag.) De Toni (Gunnill 1980a) peaked in winter. $F$. serratus showed different peaks in reproduction in different places, e.g. September in Wembury, Devon, and November in Port Erin, Isle of Man, UK (Knight \& Parke 1950). Similarly, for F. distichus, my study indicated its peak of reproduction to be in fall to winter, but another study on the same species in Puget Sound indicated that the peak of reproduction was in June (Thom 1983). Reproductive phenology could vary by a few months even among nearby populations due to different topographical aspects (Gunnill 1980a). In both my studies and the Washington example, reproductive plants were recorded throughout the year

The number of propagules produced by algae, whether in the form of eggs, spores, zygotes or germlings, is usually assessed either by counting the undischarged propagules within reproductive structures (Kain 1975, De Wreede 1986) or by counting propagules released into a known volume of sea water over a certain period of time (Anderson \& North 1966, Bhattacharya 1985, Amsler \& Neushul 1989). The former method calculates the reproductive potential of the plant and assumes that all propagules in the reproductive structure will eventually become available for recruitment. The latter method estimates the actual number available over a particular sampling period and does not consider possible further development of new propagules in the reproductive structure. This may not be a problem with some kelps as sori normally become necrotic and disintegrate after discharge of zoospores (Klinger 1984) or are abscised from the blade at the beginning of spore release (Amsler \& Neushul 1989). However, fucoids have been shown to discharge eggs over prolonged periods of time. From my study, oogonia within conceptacles were found to be in different stages of development and conceptacles of the same receptacle did not release eggs all at the same time. The latter observation was also reported by Edelstein \& Mclachlan (1975). Subrahmanya (1957) noted that gametes could still be found in deteriorating receptacles of Pelvetia fastigiata. Similarly, l observed that some receptacles collected from the field, although showing signs of necrosis, still contained oogonia. It is not certain if eggs which were not released at one time would eventually mature and be released later. It is possible that some oogonia never develop to maturity. The potential number of eggs calculated in my study (i.e. number of eggs per conceptacle $x$ number of conceptacles in the receptacle) included eggs that are yet to develop and be discharged in immature conceptacles. However, this may still be an underestimate of the maximum reproductive potential of the plant as this does not include conceptacles that have yet to develop. It is also not certain if new oogonia, hence new eggs, could develop within an 'old' conceptacle. A complete account of this potential may be impossible to obtain unless techniques can be developed to follow the complete series of events occurring within the conceptacle.

In contrast, what is critical to the dynamics of a population may not be the potential number of propagules available throughout its reproductive season, but what is available at any particular time. In my study, the number of eggs discharged at one time was inde- 
pendent of plant size and was presumably only a function of the number of reproductive plants per unit area. Discharge may be localized depending on the dispersion of reproductive plants and may not occur at the same time for all plants. The actual number of eggs available per unit time per unit area may therefore be far less than that given as estimated production in Fig. 10

Significant correlations among reproductive phenology, potential and estimated egg production, and micro-recruitment patterns (Table 4) support the idea that as more plants become reproductive, more eggs are formed to become recruits, and hence more microrecruits are detected on the settling blocks. However, the absence of corresponding peaks in macrorecruits following pulses of microrecruits in November 1986 and March 1987 suggests that a greater abundance of eggs does not always translate into more individual plants entering the population. There may be a differential survivorship of microrecruits at different times. The number of microrecruits during these peak recruitment periods was in the range of 100 to 1000 recruits per settling block, whereas the estimated number of eggs available during the same periods was $3.5 \times 10^{3}$ per $25 \mathrm{~cm}^{2}$. So at least 3 to $30 \%$ of the eggs were recruited as microrecruits during these periods. Assuming a 3 mo growth period, only 0.4 to $12 \%$ of these microrecruits survived to become macrorecruits.

Most recruitment studies have been based on macrorecruits, i.e. recruits at first detectable size, and have assumed that recruits developed from propagules recently released (Knight \& Parke 1950, Edelstein \& McLachlan 1975, Gunnill 1980a, b, 1986, Dayton et al. 1984, Reed \& Foster 1984, Ang 1985b). This assumption is reasonable if reproduction is seasonal and hence significant recruitment tends to follow peak reproduction. In my study, it may seem reasonable to attribute the presence of macrorecruits throughout the year to the continuous presence of reproductive plants. However, the absence of microrecruits in spring and summer of 1986, and summer of 1987, clearly makes this assumption less tenable. It has been speculated that propagules from the tail end of the reproductive season probably do not contribute to the population (Edelstein \& McLachlan 1975, Gunnill 1980a). It is possible that a low percentage of reproductive plants in the early summer of 1986 and 1987 may have contributed some microrecruits, but the contribution could be very small and localized and hence insignificant for the whole population. From the estimated minimum monthly egg production (Fig. 10), it is possible that no eggs were available during these periods.

On the other hand, some of the microrecruits from the peak reproductive period may have persisted and become detectable in size very much later. In a prelimi- nary experiment, I was able to maintain microrecruits in culture chambers for up to at least a year under $8 \mathrm{~h}$ light: $16 \mathrm{~h}$ dark, $10^{\circ} \mathrm{C}$ and low light $\left(20 \mu \mathrm{E} \mathrm{m}^{-2} \mathrm{~s}^{-1}\right)$, minimal nutrients (seawater changed only once every 2 to $3 \mathrm{mo}$ ). When planted out in the field, these recruits grew to detectable size (around $5 \mathrm{~mm}$ ). Moss \& Sheader (1973) reported that Halidrys siliquosa (L.) Lyngb. can germinate in darkness, and germlings can survive for $120 \mathrm{~d}$ in darkness and resume normal growth when transferred to light. Edelstein \& McLachlan (1975) noted that growth of sporelings of Fucus distichus ssp. distichus could last over a prolonged period and many remained in an embryonic stage for 5 to 6 mo. The continuous presence of macrorecruits in the population I studied may therefore be due to the existence of a 'germling bank' of microrecruits, which survive for a prolonged period and grow to detectable size only when conditions become favourable. The pattern of their survival and emergence as macrorecruits is therefore independent of the prevailing reproductive or micro-recruitment patterns. Kain (1964) pointed out the possibility of a perennating gametophyte in Laminariales that could continue to supply sporophytic recruits into the population. This is supported by Novaczek (1984) who observed that gametophytes of Ecklonia radiata (C. Ag.) J. Ag. survived $7 \mathrm{mo}$, and young sporophytes $80 \mathrm{~d}$, in darkness at $10{ }^{\circ} \mathrm{C}$ and resumed growth and reproduction when illuminated. Small fronds (Cousens 1985) or suppressed shoots (Vadas \& Wright 1986) under the canopy in Ascophyllum nodosum were suggested to serve as a 'meristem bank' that could persist in the presence of the canopy but which could fill the place of the canopy once this canopy has been removed or damaged.

The existence of a 'germling bank' in this Fucus population remains to be experimentally verified. This may involve the placement of settling blocks with known number of microrecruits under different environmental conditions, e.g. under or without Fucus canopy, and monitoring of the growth and survival of individuals over time. In a related experiment on density-dependent growth and mortality of Fucus recruits (Ang 1991a), I have observed that recruits exhibited different growth rates resulting in skewed distribution of plant sizes. What proportion of macrorecruits could have developed from the germling bank' was not evaluated. The existence of a 'germling bank' would be particularly significant if it contributes to a large number of macrorecruits. In that case, while micro-recruitment may be very patchy and episodic (see Reed et al. 1988), the existence of a 'germling bank' would tend to stabilize fluctuations in the size of the population over time.

Given the time lapse for microrecruits to develop into macrorecruits, positive correlations between macro- 
recruitment pattern and reproductive phenology and the egg production pattern are not expected. It is interesting, however, to note the negative correlation between them (Table 4 ). The peak reproductive period was also the time when Fucus plants were longest (Ang 1991b). While the number of eggs discharged during the peak reproductive period may be independent of plant size, a canopy provided by larger plants may maintain a more favourable environment for the survival of microrecruits. Hruby \& Norton (1979) observed a greater abundance of individual species colonizing slides placed underneath a canopy of Ascophyllum nodosum than in open sites. Sites beneath a canopy remain moist during low tide. This may be particularly critical for the False Creek Fucus population beginning in the spring when the period of low tide occurs during day time. When larger plants died back because of disintegration of receptacular branches or because of increased mortality, increased light penetration would likely enhance growth of microrecruits (McLachlan 1974), making them more visible within a shorter time. Since plant length is also positively correlated with reproductive phenology (Pearson's linear correlation coefficient $r=0.60, p=0.001, n=26$ ), the negative correlation between macro-recruitment pattern and reproductive phenology (as well as between estimated egg production pattern which is related to reproductive phenology) is more likely to be due to a negative correlation with plant length than with reproductive phenology per se.

Much remains to be done to illustrate the relationship between patterns of micro- and macro-recruitment. This is one area that has received little attention mainly because of logistic problems associated with its study. The dynamics of micro-recruitment may prove to be important in the overall understanding of changes in algal population structure. Problems associated with aging of algae may be less critical if size can be shown to be a substitute for age as a predictor of algal population dynamics. This in turn may allow more work to be carried out on algal population dynamics based on size.

Acknowledgements. This study was partially funded by Natural Science and Engineering Research Council of Canada grant no. 5-89872 to R. De Wreede, and by a Sigma Xi grantin-aid. I thank R. De Wreede for his supervision and advice, $M$. Weis for help with the Kontron Image Processing System and C. Lai for advice on the statistical analyses. Critical comments from R. De Wreede, P.G. Harrison, G. Sharp and R. Turkington greatly improved earlier drafts of the manuscript. This paper further benefited from very thorough and critical reviews by $M$. J. Dring, J. Pearse and an anonymous reviewer Their comments and suggestions were particularly helpful and are acknowledged with appreciation. I held an University of British Columbia Graduate Fellowship, an International Centre for Ocean Development Fellowship, an Edith Asthon Memorial Scholarship, and a Kit Malkin Scholarship during the duration of this study.

\section{LITERATURE CITED}

Amsler, C D., Neushul, M. (1989). Diel periodicity of spore release from the kelp Nereocystis luetkeana (Mertens) Postels et Ruprecht. J. exp. mar. Biol. Ecol. 134: 117-127

Anderson, E. K. North, W. J. (1966). In situ studies of spore production and dispersal in the giant kelp, Macrocystis. Proc. Int. Seaweed Symp. 5: 73-86

Ang, P. Jr O. (1985a). Phenology of Sargassum siliquosum J. Ag. and S. paniculatum J. Ag. (Sargassaceae, Phaeophyta) in the reef flat of Balıbago, Calatagan, Philippines. Proc. 5th Int. Coral Reef Symp. 5: 51-57

Ang, P. Jr O. (1985b). Studies on the recruitment of Sargassum spp. (Sargassaceae, Phaeophyta) in Balibago, Calatagan, Philippines. J. exp. mar. Biol. Ecol. 91-293-301

Ang, P. Jr O. (1991a). Natural dynamics and matrix models of a Fucus distichus (Phaeophyceae, Fucales) population in Vancouver, British Columbia, Canada. Ph. D. thesis, Univ. of British Columbia, Vancouver

Ang, P. Jr O (1991b). Age- and size-dependent growth and mortality in a population of Fucus distichus. Mar Ecol. Prog. Ser. 78: 173-187

Baardseth, E. (1970). Synopsis of biological data on knobbed wrack Ascophyllum nodosum (Linnaeus) Le Jollis. FAO Fish. Synopses No. 38 Rev. 1

Bhattacharya, D. (1985). The demography of fronds of Chondrus crispus Stackhouse. J. exp. mar Biol. Ecol. 91 $217-231$

Bird, N. L., Maclachlan, J. (1976). Control of formation of receptacles in Fucus distichus L. subsp. distichus (Phaeophyta, Fucales). Phycologia 15: 79-84

Bold, H. C., Wynne, M. J. (1985). Introduction to the algae, 2nd edn. Prentice-Hall, Inc., Englewood Cliffs

Burrows, E. M., Lodge, S. (1951). Autecology and the species problem in Fucus. J. mar biol. Ass. U.K. 30: 161-176

Caswell, H. (1989). Matrix population models. Sinauer Associates, Inc., Sunderland

Chapman, A. R. O. (1984a). Reproduction, recruitment and mortality in two species of Laminaria in southeast Nova Scotia. J. exp. mar Biol. Ecol. 78: 99-110

Chapman, A. R. O. (1984b). Demography. In: Littler, M. M., Littler, D. S. (eds.) Handbook of phycological methods. Ecological field methods: macroalgae. Cambridge Univ. Press, Cambridge, p. 251-268

Chapman, A. R. O. (1986). Age versus stage: an analysis of age and size specific mortality and reproduction in a population of Laminaria longicruris. J. exp. mar. Biol. Ecol. 97 : $113-122$

Chapman, A. R. O., Goudey, C. L. (1983). Demographic study of the macrothallus of Leathesia difformis (Phaeophyta) in Nova Scotia. Can. J. Bot. 61: 319-323

Cousens, R. (1985). Frond size distributions and the effects of the algal canopy on the behaviour of Ascophyllum nodosum (L.) Le Jolis. J. exp. mar Biol. Ecol. 92: 231-249

David, H. M. (1943). Studies in the autecology of Ascophyllum nodosum Le Jol. J. Ecol. 31: 178-198

Dayton, P. K. (1973). Dispersion, dispersal, and persistence of the annual intertidal alga, Postelsia palmaeformis Ruprecht. Ecology 54: 433-438

Dayton, P. K., Currie, V., Gerrodette, T., Keller, B. D., Rosenthal, R., Ven Tresca, D. (1984). Patch dynamics and stability of some California kelp communities. Ecol. Monogr. 54: 253-289

De Wreede, R. E. (1984). Growth and age class distribution of Pterygophora californica (Phaeophyta). Mar Ecol. Prog. Ser 19: 93-100

De Wreede, R. E. (1986). Demographic characteristics of 
Pterygophora californica (Laminariales, Phaeophyta). Phycologia 25: 11-17

De Wreede, R. E., Klinger, T (1988). Reproductive strategies in algae. In: Lovett Doust, J., Lovett Doust, L. (eds.) Plant reproductive ecology. Patterns and strategies. Oxford Univ. Press, New York and Oxford, p. 267-284

Doherty, P., Williams, D. McB. (1988). The replenishment of coral reef fish populations. Oceanogr. mar. Biol. An. Rev. 26: $487-551$

Edelstein, T., McLachlan, J. (1975). Autecology of Fucus distichus ssp. distichus (Phaeophyceae: Fucales) in Nova Scotia, Canada. Mar. Biol. 30: 305-324

Goodman, L. A., Kruskal, W. H. (1954). Measures of associations for cross classifications. J. Am. Stat. Ass. 49: $732-764$

Gray, L. N., Williams, J. S. (1975). Goodman and Kruskal's tau b: multiple and partial analogs. Proc. Soc. Stat. Sec., Am. Stat. Ass., p. $444-448$

Gunnill, F. C. (1980a). Demography of the intertidal brown alga Pelvetia fastigiata in southern California, U.S.A. Mar. Biol. 59: 169-179

Gunnill, F. C. (1980b). Recruitment and standing stocks in populations of one green alga and five brown algae in the intertidal zone near La Jolla, California during 1973-1977. Mar. Ecol. Prog. Ser 3: 231-243

Gunnill, F. C. (1986). Demography of Cystoseira osmundacea and Halidrys dioica (Phaeophyta, Cystoseiraceae) at La Jolla, California, USA. Botanica mar. 29: 137-146

Harper, J. L. (1977). Population biology of plants. Academic Press, New York

Hoffmann, A. J. (1987). The arrival of seaweed propagules at the shore: a review. Botanica mar 30: 151-165

Hruby, T., Norton, T A. (1979). Algal colonization on rocky shores in the Firth of Clyde. J. Ecol. 67: 65-77

Hymanson, Z. P., Reed, D. C., Foster, M. S., Carter, J. W. (1990). The validity of using morphological characteristics as predictors of age in kelp Pterygophora californica (Laminariales, Phaeophyta). Mar. Ecol. Prog. Ser. 59: 295-304

Jaffe, L. (1954). Stimulation of the discharge of gametangia from a brown alga by a change from light to darkness. Nature, Lond. 174: 743

Kain, J. M. (1964). Aspects of the biology of Laminaria hyperborea III. Survival and growth of the gametophytes. J. mar. biol. Ass. U.K. 44: 415-433

Kain, J. M. (1975). The biology of Laminaria hyperborea VII. Reproduction of the sporophyte. J. mar. biol. Ass. U.K. 55: $567-582$

Keser, M., Vadas, R. L., Larson, B. R. (1981). Regrowth of Ascophyllum nodosum and Fucus vesiculosus under various harvesting regimes in Maine, USA. Botanica mar. 24 : 29-38

Klinger, T (1984). Allocation to meiospore production in annual and perennial representatives of the genus Laminaria. M. Sc. thesis, Univ. of British Columbia, Vancouver

Knight, M., Parke, M (1950). A biological study of Fucus vesiculosus L. and F. serratus L. J. mar. biol. Ass. U.K. 26: 439-514

Lazo, M. L., McLachlan, J. L. (1990). Reproduction of Chondrus crispus Stackhouse (Rhodophyta, Gigartinales) in sublittoral Prince Edward Island, Canada. J, appl. Phycology $1: 359-365$

McLachlan, J. (1974). Effects of temperature and light on growth and development of embryos of Fucus edentatus and $F$, distichus ssp. distichus. Can. J. Bot. 52: 943-951

McLachlan, J., Chen, L. C.-M., Edelstein, T (1971). The culture of four species of Fucus under laboratory condi tions. Can. J. Bot. 49: 1463-1469

Moss, B. Sheader, A. (1973). The effect of light and temperature upon the germination and growth of Halidrys siliquosa (L.) Lyngb. (Phaeophyceae, Fucales). Phycologia 12: $63-68$

Niemeck, R. A., Mathieson, A. C. (1976). An ecological study of Fucus spiralis L. J. exp. mar. Biol. Ecol. 24: 33-48

Norton, T. A. (1981). Gamete expulsion and release in Sargassum muticum. Botanica mar. 24: 465-470

Norton, T. A., Mathieson, A. C., Neushul, M. (1981). Morphology and environment. In: Lobban, C. S., Wynne, M. J (eds.) The biology of seaweeds. Univ of California Press, Berkeley and Los Angeles, p. 421-451

Novaczek, I. (1981). Stipe growth rings in Ecklonia radiata (C.Ag.) J.Ag. (Laminariales). Br. Phycol. J. 16: 363-371

Novaczek, I. (1984). Response of Ecklonia radiata (Laminariales) to light at $15^{\circ} \mathrm{C}$ with reference to the field light budget at Goat Island Bay, New Zealand. Mar Biol. 80: 263-272

Pacheco-Ruiz, I., Garcia-Esquivel, Z., Aguilar-Rosas, L. E. (1989). Spore discharge in the carragenophyte Gigartina canaliculata Harvey (Rhodophyta, Gigartinales). J. exp. mar. Biol. Ecol. 126: 293-299

Powell, H. T (1957). Studies in the genus Fucus L. I. Fucus distichus L. emend. Powell. J. mar. biol. Ass. U.K. 36 $407-432$

Pringle, J. D. (1986). Swarmer release and distribution of lifecycle phases of Enteromorpha intestinalis (L.) (Chlorophyta) in relation to environmental factors. J. exp. mar. Biol. Ecol. 100: 97-111

Reed, D. C. (1990). The effects of variable settlement and early competition on patterns of kelp recruitment. Ecology 71 : $776-787$

Reed, D. C., Foster, M. S. (1984). The effects of canopy shading on algal recruitment and growth in a giant kelp forest. Ecology 65: 937-948

Reed, D. C., Laur, D. R., Ebeling, A. W. (1988). Variation in algal dispersal and recruitment: the importance of episodic events. Ecol. Monogr. 58: 321-335

Rice, E. L., Chapman, A. R. O. (1985). A numerical taxonomic study of Fucus distichus (Phaeophyta). J. mar. biol. Ass. U.K. 65: 433-459

Rosenthal, R. J., Clarke, W. D., Dayton, P. K. \{1974\}. Ecology and natural history of a stand of giant kelp, Macrocystis pyrifera, off Del Mar, California. Fish. Bull. U.S. 72: $670-684$

Roughgarden, J., Gaines, S., Possingham, H. (1988). Recruitment dynamics in complex life cycles. Science 241: $1460-1466$

Sale, P. F (1990). Recruitment of marine species: is the bandwagon rolling in the right direction? TREE 5: 25-27

Santelices, B. (1990). Patterns of reproduction, dispersal and recruitment in seaweeds. Oceanogr mar. Biol. A. Rev. 28: $177-276$

Scagel, R. F., Gabrielson, P. W., Garbary, D. J., Golden, L., Hawkes, M. W., Lindstrom, S. C., Oliveira, J. C., Widdowson, T. B. (1989). A synopsis of the benthic marine algae of British Columbia, southeast Alaska, Washington and Oregon. Dept of Botany, Univ. of British Columbia, Vancouver

Schiel, D. R. (1985a). A short-term demographic study of Cystoseira osmundacea (Fucales: Cystoseiraceae) in central California. J. Phycol. 21 99-106

Schiel, D. R. (1985b). Growth, survival and reproduction of two species of marine algae at different densities in natural stands. J. Ecol. 73: 199-217

Shannon, R. K., Crow, G. E., Mathieson, A. C. (1988). Seasonal abundance and recruitment patterns of Petalonia fascia 
(O. F. Muller) Kuntze and Scytosiphon lomentaria (Lyngbye) Link var. lomentaria in New Hampshire, U.S.A. Botanica mar. 31. 207-214

Sideman, E. J., Mathieson, C. (1983). The growth, reproductive phenology, and longevity of non-tide pool Fucus distichus (L.) Powell in New England. J. exp. mar Biol. Ecol. 68: 111-127

Sokal, R. R., Rohlf, F. J. (1981). Biometry, 2nd edn. W. H. Freeman and Co., New York

Subrahmanya, R. (1957). Observations on the anatomy, cytology, development of reproductive structures, fertilization and embryology of Pelvetia canaliculata Dcne. et Thur. Part IlI. The liberation of reproductive bodies, fertilization and embryology. J. Indian Bot. Soc. 36: 373-395

This article was submitted to the editor
Thom, R. M. (1983). Spatial and temporal patterns of Fucus distichus ssp. edentatus (de la Pyl.) Pow. (Phaeophyta: Fucales) in central Puget Sound. Botanica mar. 26: $471-486$

Umezaki, I. (1984). How many eggs will be discharged from the plant of Sargassum horneri? Hydrobiologia 116/117. $398-402$

Underwood, A. J., Fairweather, P. G. (1989). Supply-side ecology and benthic marine assemblages. TREE 4: 16-20

Vadas, R. L., Wright, W. A. (1986). Recruitment, growth and management of Ascophyllum nodosum. Actas Il Congr Algas Mar. Chilenas: 101-113

Wilkinson, L. (1988). SYSTAT: The system for statistics. SYSTAT, Inc., Evanston

Manuscript first received: March 19, 1991

Revised version accepted: August 12, 1991 